\title{
Analysis of the reclamation canal condition and cleaning methods
}

\author{
Khamzat Abdulmazhidov* \\ Federal State Budgetary Educational Institution of Higher Education "Russian State Agrarian \\ University-Moscow Timiryazev Agricultural Academy", Timiryazevskaya street, 49, 127550 \\ Moscow Russian Federation
}

\begin{abstract}
The operating quality of reclamation drainage and irrigation systems depends on the condition of their main elements. The main elements of reclamation systems are canals with various profiles, ranging from rectangular to parabolic. The most widespread in land reclamation are canals with a trapezoidal profile. At the same time, it is possible to note that the natural production characteristics of reclamation systems are quite diverse, this issue is especially relevant for geometric parameters of the canals. In this case, the stable slopes of canals, restoring their profile and cleaning from sediments and silting can only be provided by special complexes of machines. Knowledge of defect types and causes in reclamation canals allows them to be prevented and eliminated in a timely manner. One of the main tasks in this case is to ensure the stability of canal slopes.
\end{abstract}

\section{Introduction}

The high-quality functioning of reclamation systems is directly related to the condition of drainage or irrigation canals. During the flood period, it becomes necessary to discharge excess water; for this, canals that meet operating requirements are required, that is, the canals shall have design geometric dimensions. During a drought period, moisture shall be maintained in compliance with the water supply regime, in this case, various structures on the canals are used to save water, for example, locks, their closing makes it possible to keep moisture in the reclamation system. In addition, locks are an element of water level regulation in a constantly changing water situation, depending on natural and seasonal conditions. During operation, the initial design cross-section of the canals changes, sediments, siltation and vegetation appear, in some cases, when the frequency and timing of current and major repairs is violated, the appearance of small shrubs is observed. These factors affect the capacity of canals, respectively, and system operation as a whole. At first glance, economically, periodic cleaning of reclamation canals as part of current and major repairs in comparison with other types of agricultural production (for example, grain growing) does not bring economic benefits, however, various disasters and the elimination of their consequences confirms the need for cleaning and renewal of canals. Such cataclysms include

${ }^{*}$ Corresponding author: hamzat72@mail.ru 
floods during the flood period and fires during dry seasons. Standard sizes of drainage canals are shown in table 1 .

Table 1. Standard sizes of canal cross-sections in the earthen bed of drainage systems

\begin{tabular}{|c|c|c|c|}
\hline Canal name & Construction depth, $\mathrm{m}$ & Canal width, $\mathrm{m}$ & $\begin{array}{l}\text { Ratio of } \\
\text { slope }\end{array}$ \\
\hline \multicolumn{4}{|c|}{ 1. Canals made by general construction machines } \\
\hline $\begin{array}{l}\text { Conductive } \\
\text { Regulator } \\
\text { Catchwater and intercepting } \\
\text { canals }\end{array}$ & $\begin{array}{l}\text { from } 0.8 \text { to } 1.5 \\
\text { from } 1.5 \text { to } 2.5 \\
\text { from } 1.5 \text { to } 3.0\end{array}$ & $\begin{array}{l}0.4 ; 0.6 ; 0.8 \\
0.6 ; 0.8 ; 1.0 \\
0.6 ; 0.8 ; 1.0 ; 1.5\end{array}$ & $\begin{array}{l}1.0 ; 1.5 ; 2.0 \\
1.5 ; 2.0 ; 2.5 \\
1.5 ; 2.0 ; 2.5\end{array}$ \\
\hline \multicolumn{4}{|c|}{ 2. Canals made by specialized machines } \\
\hline Regulator & $\begin{array}{c}\text { from } 0.8 \text { to } 1.0 \\
\text { from } 1.0 \text { to } 1.2 \text { from } \\
1.2 \text { to } 1.7\end{array}$ & $\begin{array}{c}0.25 ; \\
0.25 ; 0.40 ; 0.6 \\
0.25 ; 0.40 ; 0.6\end{array}$ & $\begin{array}{c}1.0 \\
1.0 ; 1.5\end{array}$ \\
\hline
\end{tabular}

The costs incurred in the process of reclamation systems, agricultural production and forest areas renewal in general after periodic floods or after fires (for example, fires in the European part of the Russian Federation in 2010) are disproportionately high compared to what has to be implemented during current and major repairs of drainage systems. Routine repair of reclamation canals means their cleaning, including the bottom and slopes, from vegetation, sediment and silting; elimination of landslides and defects, formation of elements for slope securing. The bottom is deepened up to the initial design marks, developed sediments are distributed along the canal [1].

Overhaul of the canals is accompanied by canal deepening and widening, slope planning, soil leveling and silting removed from the canal; in some cases, it is allowed to change the canal route. The most time-consuming operations in the overhaul are slope securing with concrete slabs, a plank wall and fascines. Overhaul of canals can be performed using special canal cleaning machines, and in cases where the canal depth exceeds $2 \mathrm{~m}$, using single-bucket general construction excavators with special working bodies. Routine repair and maintenance of open canals is most efficiently performed by special canal cleaners with active working bodies of continuous action (milling or rotary type). Termination of current repairs and overhaul of reclamation canals of the drainage network result in overgrowth and change in the canal profile (Fig. 1), which also results in a violation of its capacity.

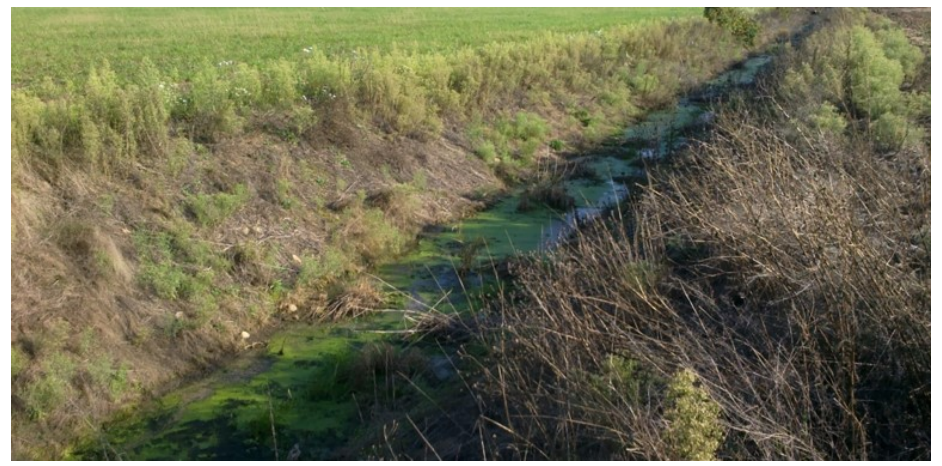

Fig. 1. Drainage canal condition during long-term operation without current and major repairs

High-quality use of reclamation lands is achieved with modern and efficient performance of a wide range of repair and renewal operations using special machines of high quality and productivity. At present, the most optimal method for cleaning and renewal of reclamation canals is a complex mechanized method, implying implementation of all basic and auxiliary 
operations using machines and mechanisms. This method combines machines and mechanisms so that when they are fully loaded, the minimum cost of works is ensured at their maximum productivity. It is also worth mentioning that some sections of the canals still require the manual labor of canal repairmen, it applies to those sections where the use of special machines is impossible, for example, sections under bridges and near locks, etc. [2].

Another important component in the formation of a complex mechanized method is the number of machines in a complex. On the one hand, a large number of machines should be selected and interconnected for full load with the lowest cost of work at maximum productivity, on the other hand, a large number of machines of a particular complex is already economically unprofitable. There is no single special machine that performs all types of cleaning and renewal operations, it also follows that a significant increase in the number of machines and their standard sizes in one complex can provide high-quality cleaning, but there will also be significant costs. Thus, the optimal value of the number of machines within one complex for cleaning works of reclamation systems becomes a very important task. A certain scope of canal cleaning and renewal operations calls for a certain mechanical equipment from the enterprise or economy, which is determined by the ratio of the balance cost of the fleet of machines and mechanisms $B_{m}$ to the cost of repair and renewal operations $C_{\Gamma}$, performed during a year:

$$
M_{o}=\frac{5_{M}}{C_{\Gamma}}
$$

When determining the composition of the optimal complex of machines, it is important to take into account both the technical and operational and technical and economic machine parameters, the first group of indicators includes productivity, and the second group is the cost of cleaning operations. In general, the performance of a canal cleaning machine is the volume of production (i.e., sediment and silt volume) produced by the machine per unit of time. By integrating the units of sediment and silt volumes over time, performance can be determined. Thus, it is important to understand the scope of land reclamation farm cleaning operations [3].

The use of high-performance powerful machines can be effective for large volumes of operations, and, such machines are mainly used in the construction of reclamation system canal. The scope of performed cleaning operations is not high; moreover, the distribution of sediments along the canal length is extremely uneven. Their highest number is observed at the junctions with other canals, as well as at the junctions of the drainage pipes with the canal.

The complex of canal cleaning machines can contain main and auxiliary machines. To determine the number of main machines at the preliminary stage, the planned intensity of the studied type of operations is calculated:

$$
I_{i}=\frac{V_{i} K_{\mathrm{Hep}}}{T_{i}}
$$

where $V_{i}$ is a scope of studied operation type; $K_{\text {нер }}$ is a coefficient of uneven performance of operations in the studied period; $T_{i}$ is a deadline of operations. The required number of machines in this case is determined by the formula:

$$
n_{i}=\frac{I_{i}}{\Pi_{i}}
$$

where $T_{i}$ is the design performance of machines under specific operating conditions. 


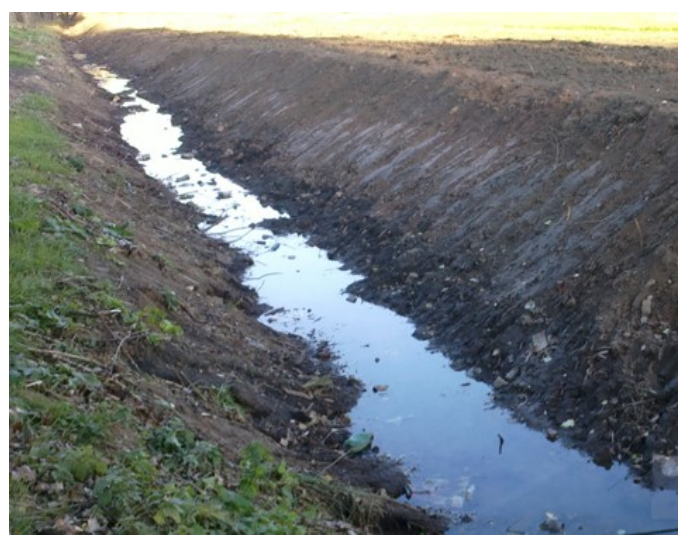

Fig. 2. Reclamation canal in the process of cleaning and renewal

An important characteristic for maintenance of reclamation canals is the frequency of repair operations. Here the cycles of cleaning operations are considered, they are divided into the overhaul period, the overhaul cycle and the overhaul cycle structure. The operation of canals and their structures between two next scheduled repairs refers to the overhaul period, the operation of networks and structures between two next major overhauls refers to the overhaul cycle. The overhaul cycle structure implies alternating repairs of a system or a separate canal $[4,5]$.

As part of the maintenance of the canals of the drainage network, cleaning operations are performed annually, the specific volumes of sediment and siltation for the drainage network are low and range from 0.015 to $0.025 \mathrm{~m}^{3}$. However, these values increase over time and can range from 0.1 to $0.3 \mathrm{~m}^{3}$.

Mechanical cleaning of canals is complicated by the fact that reclamation systems include a large number of various standard sizes of canals, various maintenance and repair operations. It is often necessary to deal with canals made in a cut, a semi-cut-and-fill or in a fill. It is reflected in the designs of canal cleaning machines. Some inconveniences when performing mechanized canal cleaning are caused by canal structures such as bridges, crossings, outlets, etc.

\section{Materials and Methods}

The formation of machine complexes for canal cleaning is usually performed with selection of the main leading machine. In this study, a canal cleaner with a bucket moving during operation on rigid guides along the canal axis is taken as the leading machine. The operating equipment, including a double telescopic boom, rigid guides made of two channels and a bucket on rollers, is installed in the form of a side hitch to a caterpillar tractor. The machine, moving along the canal berm, works positionally to clean the bottom of the canal from sediments and silting. The first version of the working body, a bucket, has a rectangular profile and is designed to clean the bottom of canals, 0.4 and $0.6 \mathrm{~m}$ wide, with fixed slopes. Canals with fixed slopes are usually present on drainage systems in Kaliningrad region and Belarus. The second version of the working body, a bucket, has a trapezoidal profile and is designed to clean the bottom and slope parts adjacent to the bottom. Such profiles of drainage canals are most common and have large lengths in the European part of the Russian Federation $[6,7,8]$.

If a canal cleaner with a bucket on rigid guides is considered as the main machine of one of many possible complexes, then other operations, such as mowing of canal slopes, collecting and moving sediment and silt removed from the canal, can be performed by a canal 
trowel and a single-bucket excavator based on a pneumatic-wheeled tractor with a bulldozer blade.

It was necessary to ensure the lowest traction resistance during cleaner bucket operation. To determine the traction forces, reduced models of rectangular and trapezoidal profile buckets were designed and manufactured. Laboratory works to determine traction resistance with models of working bodies was performed on a soil tray, which is a metal container with soil and rigid guides on its walls. A trolley with a model can move along rigid guides, excavating the ground, with characteristics as close as possible to the soil-alluvial environment in natural production conditions. Digging efforts were recorded by special sensors and transmitted to a computer. The obtained experimental data were processed and then recalculated to working bodies in full size. Traction forces as a function of optimization were determined depending on the digging depth (thickness of chips removed by the bucket).

\section{Results and Discussion}

The obtained valuesof traction forces for the model and recalculated for the bucket in full size turned out to be quite sufficient for the hydraulic system of the base tractor in combination with a four-speed pulley block. The use of a trapezoidal section bucket results in certain changes in operational characteristics: firstly, the bucket capacity increases, respectively, the bucket mass with soil also increases, all this can affect the machine stability during operation; secondly, an increase in the bucket mass with soil means an increase in loads, requiring strength calculations of the working equipment structures; thirdly, the working equipment hydraulic drive is to be checked.

The stable operation of the canal cleaner is ensured through the use of a tracked base tractor, as well as the use of a counterweight with a variable reach. Preliminary strength calculations in Inventor Pro show that the safety factor for steel structures is within acceptable limits.
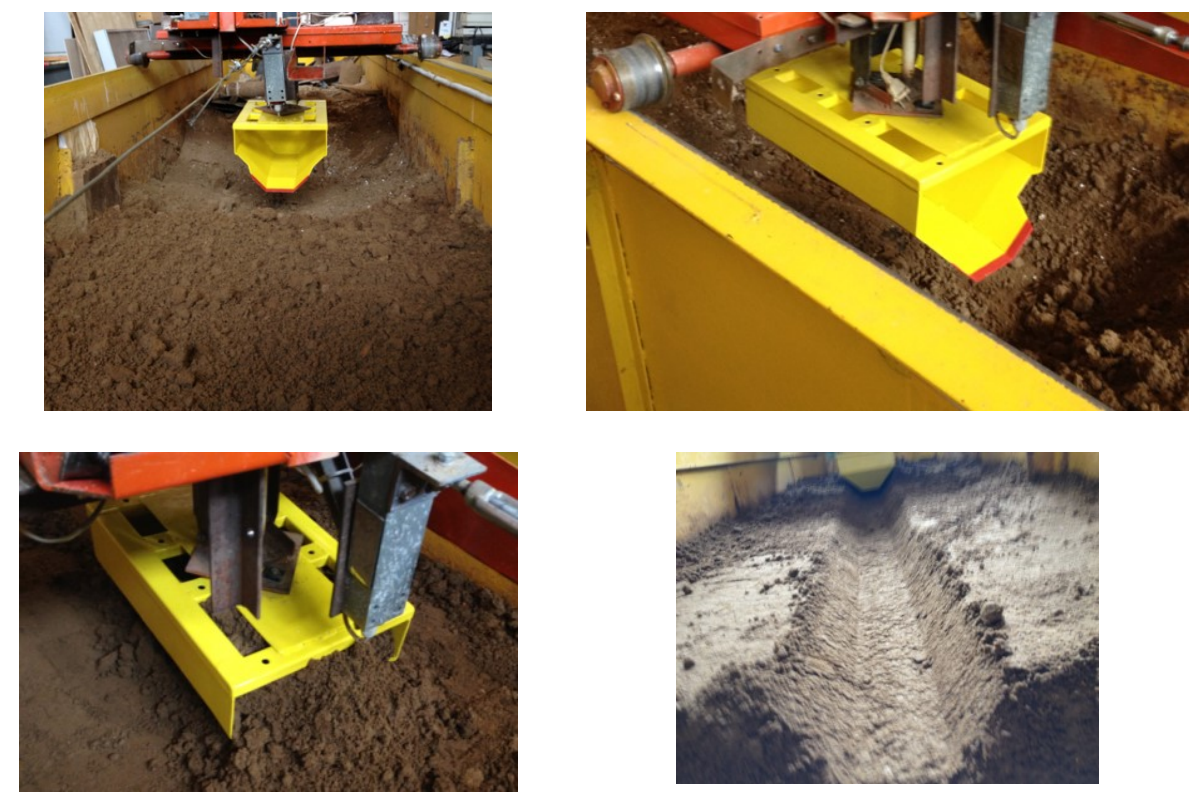

Fig. 3. Testing the working body model of a canal cleaner in laboratory conditions 
In recent years, the volume of maintenance and repair operations on reclamation canals has become very significant, it requires cleaning machines of high productivity, mobility and maneuverability, as well as not causing problems with transportation from one system to another or from one canal to another. In this sense, the most demanded machines will be continuous action machines, in comparison with cyclic action machines, they have high technical and operational indicators. However, a canal cleaner with a bucket movement along the canal axis has a high quality of cleaning operations, especially when it comes to ensuring the required slope. Laboratory tests with a model bucket and field studies with a life-size working body showed the high quality of cleaning operations and productivity.

\section{Conclusions}

1. The analysis of the studies showed that as the leading machine of the cleaning complex for reclamation drainage canals, up to $2 \mathrm{~m}$, a canal cleaning machine with a bucket longitudinal along the canal axis can be used with the greatest efficiency.

2. Calculations of canal cleaner stability were made taking into account the stability factor of 1.4 adopted by Rostekhnadzor. The stability calculations include all design changes in the working equipment that could result in an increase in weight. An analysis of graphical dependencies of the bucket capacity on its reach showed that when using a tracked tractor as a base with reach of about 5-6 meters, it makes sense to focus on the bucket capacity of 0.25 $\ldots 0.3 \mathrm{~m}^{3}$, and for reach up to $3-4$ meters, the capacity can be increased to $0.40 \ldots 0.45 \mathrm{~m}^{3}$.

3. The first main parameter in the design of working equipment is the depth of the canal to be cleaned. The second main parameter of the bucket is its width, this parameter can be considered initially selected, as it is related to the width along the bottom of most drainage canals. Therefore, the minimum bucket width can be taken equal to $400 \mathrm{~mm}$, in cases where the width along the bottom is $600 \mathrm{~mm}$, a replacement bucket of the same width can be used. For canals with a bottom width of $800 \mathrm{~mm}$, a $400 \mathrm{~mm}$ wide double pass bucket can be used. In the process of laboratory tests and field studies, the main advantage of the canal cleaner with the bucket movement along the canal axis was confirmed - the high quality of cleaning operations. Tests have also identified ways to increase leading canal cleaner performance by improving bucket design and matching bucket length and height with its width. Technological studies have revealed the optimal dimensions of buckets (width, length and height).

4. As experimental studies demonstrated, the traction forces at soil digging with canal cleaner buckets were determined, they are converted to working bodies in full size and may well be implemented by the hydraulic drive of the base machine.

\section{References}

1. N.N. Dubenok, Yu.G. Yanko, A. F. Petrushin, R. V. Kalinichenko, Modern Problems of Remote Sensing of the Earth from Space, 16(3), 96 (2019)

2. I.P. Kruzhilin, N.N. Dubenok, M.A. Ganiev, K.A. Rodin, S.D. Fomin, IOP Conference Series: Earth and Environmental Science, 341(1), 012100 (2019)

3. N.N. Dubenok, A.V. Gemonov, A.V. Lebedev, IOP Conference Series: Earth and Environmental Science, 548(8), 082014 (2020)

4. F. Abdrazakov, A. Rukavishnikov, O. Miheeva, C. Churkina, M. Yarmashevich, IOP Conference Series: Materials Science and Engineering, 883(1), 012209 (2020)

5. F.K. Abdrazakov, A.A. Rukavishnikov, A.V. Povarov, Y.E. Trushin, E3S Web of Conferences, 140, 09009 (2019) 
6. N. Martinova, K. Shavazov, N. Telovov, S. Toigambayev, S. Yusupov, IOP Conference Series: Earth and Environmental Science, 614(1), 012145 (2020)

7. A.A. Rukavishnikov, Materials of the VII Intramural International Scientific and Practical Conference Saratov State Agrarian University Named after N. I. Vavilov, 233 (2019)

8. Yu.M. Kosichenko, Mssu Bulletin, 7, 114 (2016) 